\title{
REMOTS sediment profiles around an exploratory drilling rig in the southern North Sea
}

\author{
Heye Rumohr, Hartmut Schomann
}

Institut für Meereskunde, Düsternbrooker Weg 20, W-2300 Kiel, Germany

\begin{abstract}
During the Bremerhaven Workshop in the southern North Sea, REMOTS sediment profile images (SPI) were recorded in order to supplement the benthic component of the workshop and other environmentally relevant parameters investigated along a spatial gradient at an abandoned exploratory drilling site off the Dutch coast. The sampling stations were in accordance with the other studies, but due to bad weather conditions only a small proportion of the intended samples were taken. The profile data were supplemented by video recordings of the sediment surface features taken on a second cruise. The results presented here have important implications for the interpretation of other benthic and sediment samples, and may help to interpret some enigmatic workshop data.
\end{abstract}

\section{INTRODUCTION}

Development of the REMOTS technology by Rhoads \& Germano (1987) in the last 20 yr makes it possible to a view the upper sediment layers as if through an inverted periscope. This has made the retrieval of a variety of abiotic and biotic measurements much easier and quicker compared with earlier methods, i.e. by cores. The approach became widely adopted in Europe after Rhoads introduced it as a new benthic monitoring technique (Rhoads \& Germano 1987). Its use was demonstrated recently at a workshop on imaging methods in Kiel where groups reported on their results using REMOTS technology. These applications included its use on dumping sites, monitoring of siltation and sedimentation, environmental impact assessment of coastal cage-net aquaculture and pure scientific applications such as benthic and sedimentological questions (Rumohr 1991a, b).

Traditional sampling methods such as grabs, dredges and cores often fail to record the sediment surface accurately since they disturb considerably the sea floor under investigation. Often the sediment surface is blown away by the bow-wave of such instruments when lowered to the bottom. One way to overcome this problem is to use non-impact methods such as video and still photography or other imaging methods where a low impact on the sediment has been proven by replicate controls. Nevertheless interpretation of the results is dependent on experience in local conditions, i.e. faunal composition as well as sedimentological features. In addition sediment profile imaging provides evidence of hidden contamination in lower sediment layers, examples of which are presented in this study.

\section{MATERIAL AND METHODS}

During a cruise with RV 'Aurelia' (12 to 16 March) 58 REMOTS frames were taken with a modified REMOTS sediment profile camera (Benthos 3731) in the southern North Sea around an abandoned exploratory drilling site in $40 \mathrm{~m}$ water depth (see Daan et al. 1992). The intended spatial sampling scheme could not be carried out because of unusually bad weather conditions during the whole period. So 7 stations were sampled on a spatial gradient leading in a direction of approximately

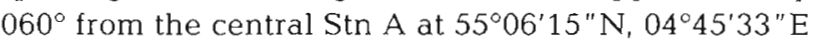
(distances: $5000 \mathrm{~m}, \mathrm{Stn} \mathrm{G}_{;} 2000 \mathrm{~m}$, Stn F; $1000 \mathrm{~m}$, Stn $\mathrm{E}_{\text {; }}$ 


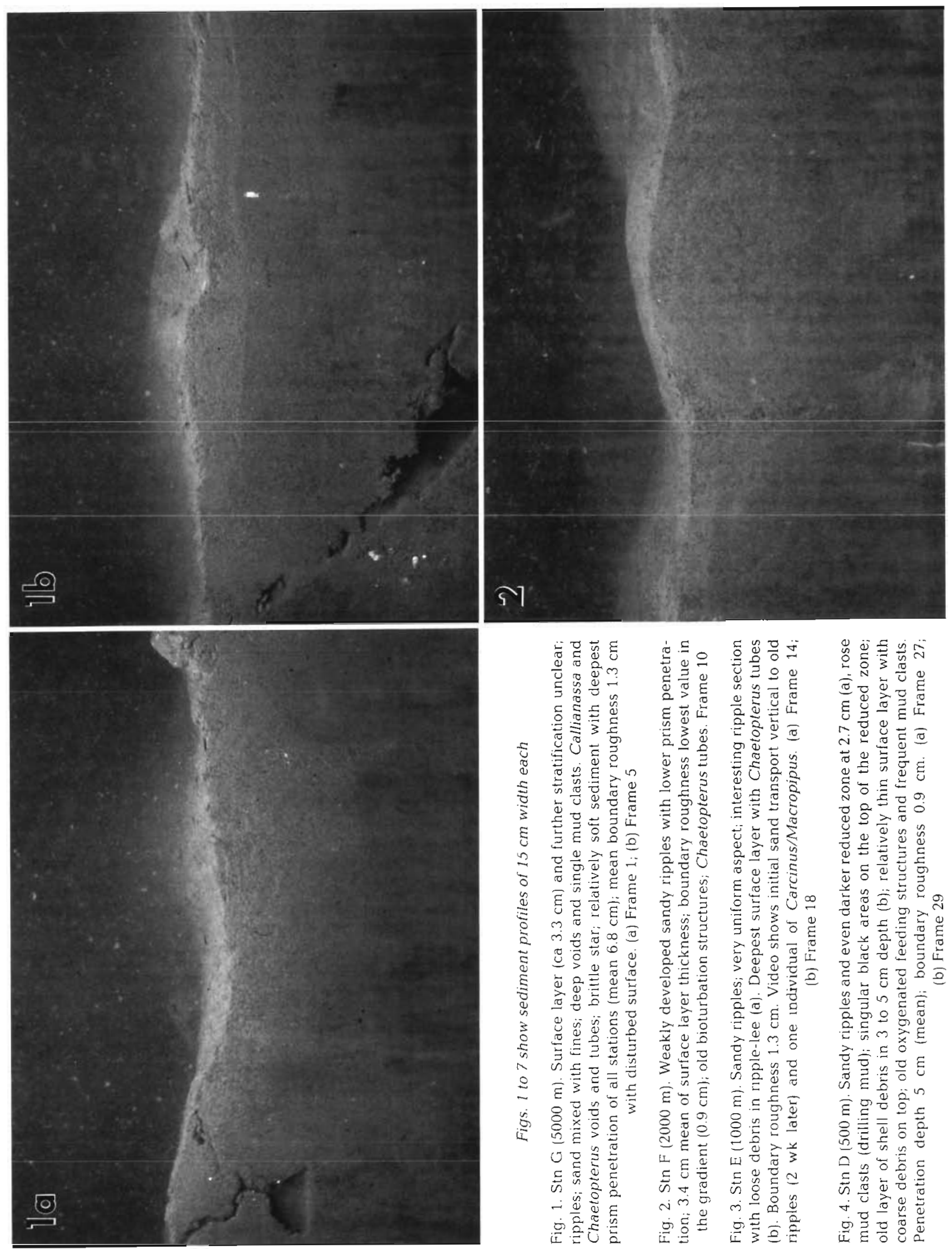




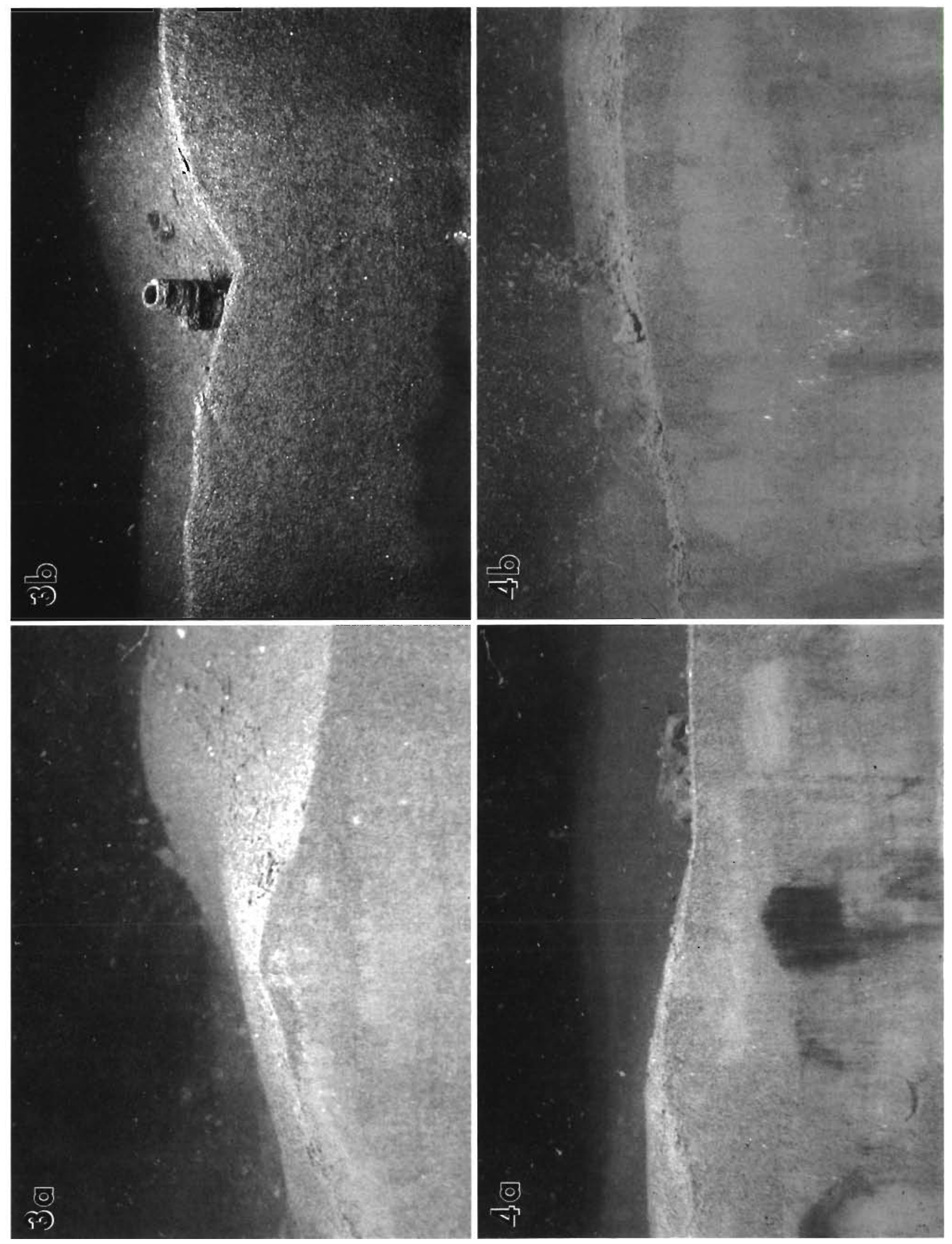




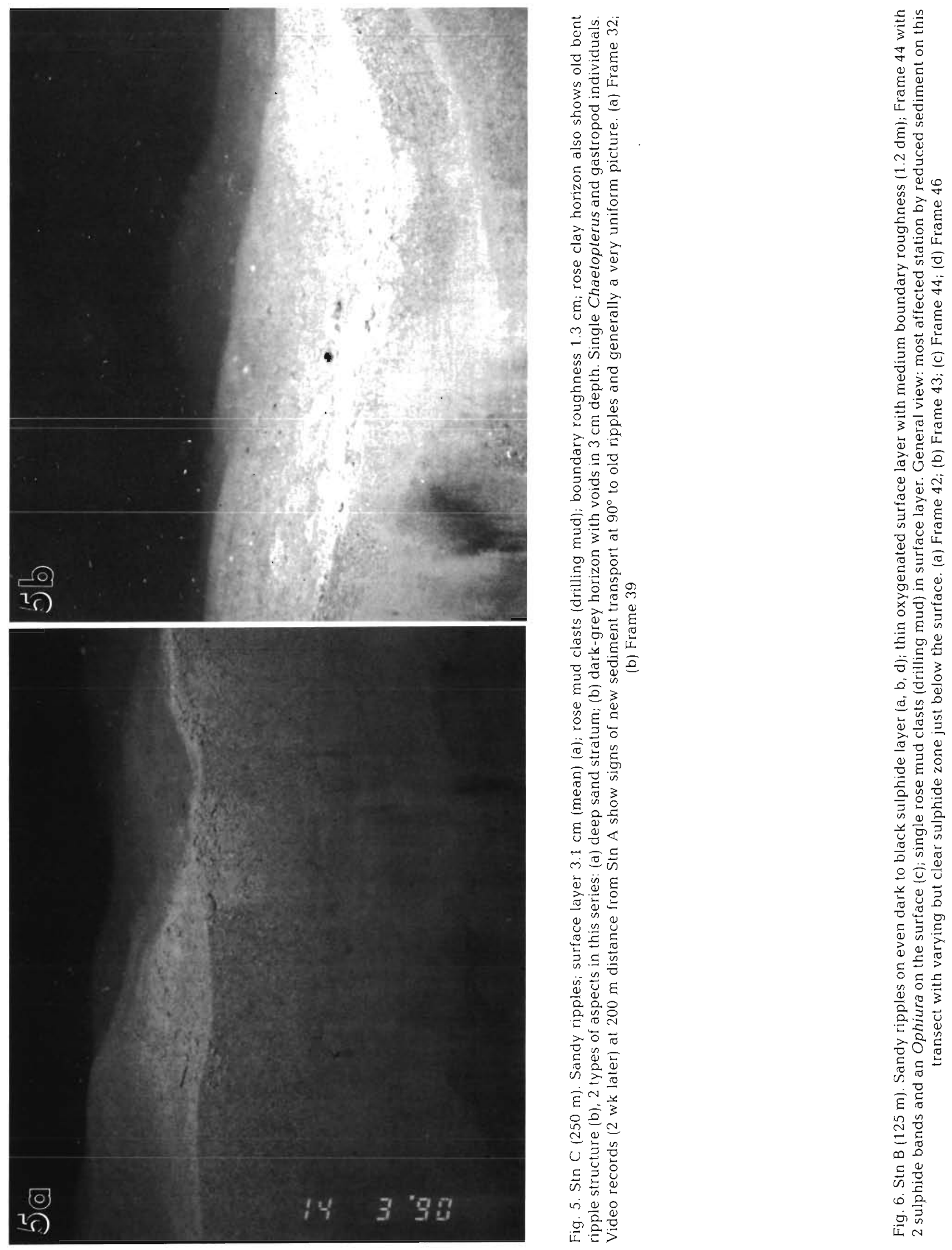




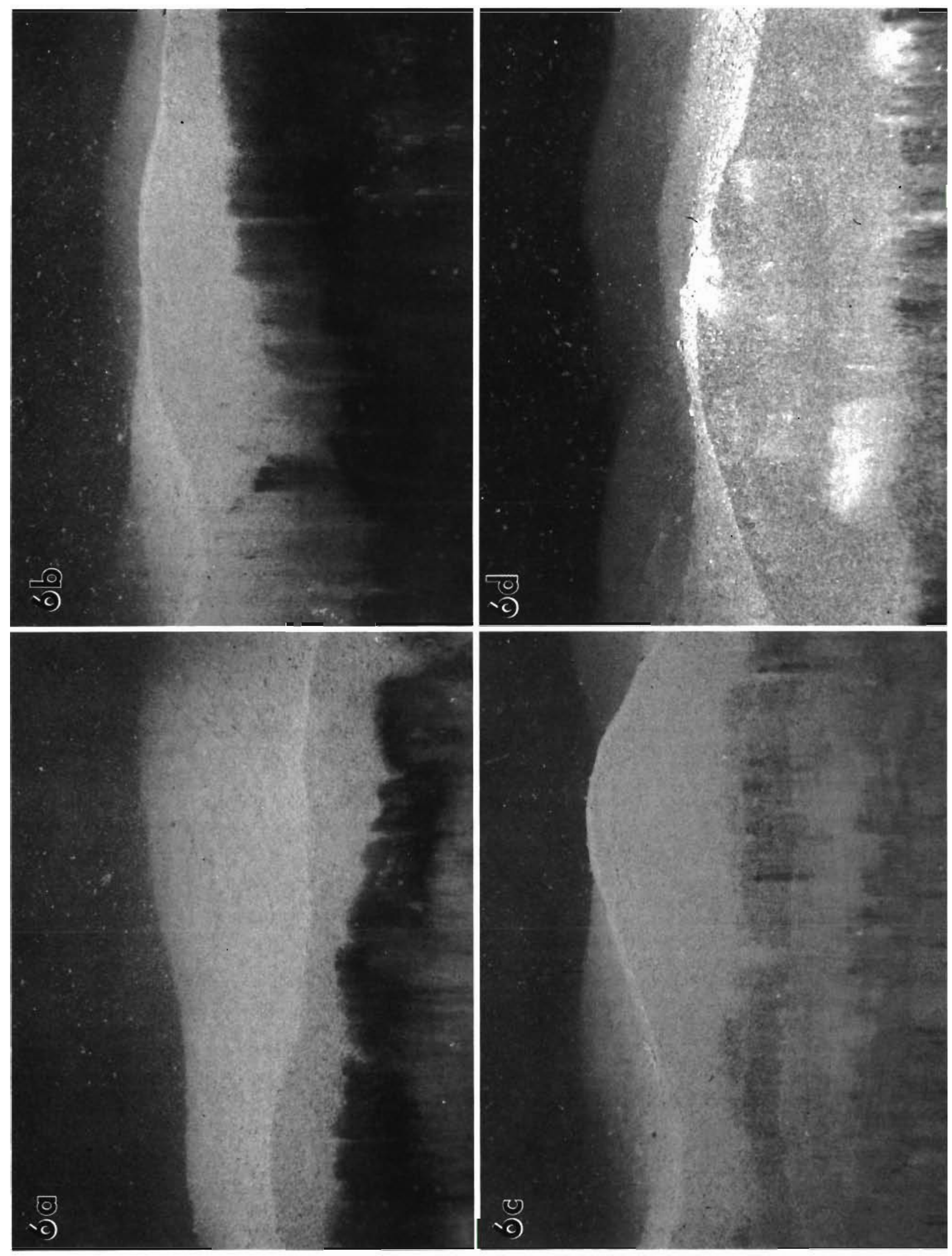




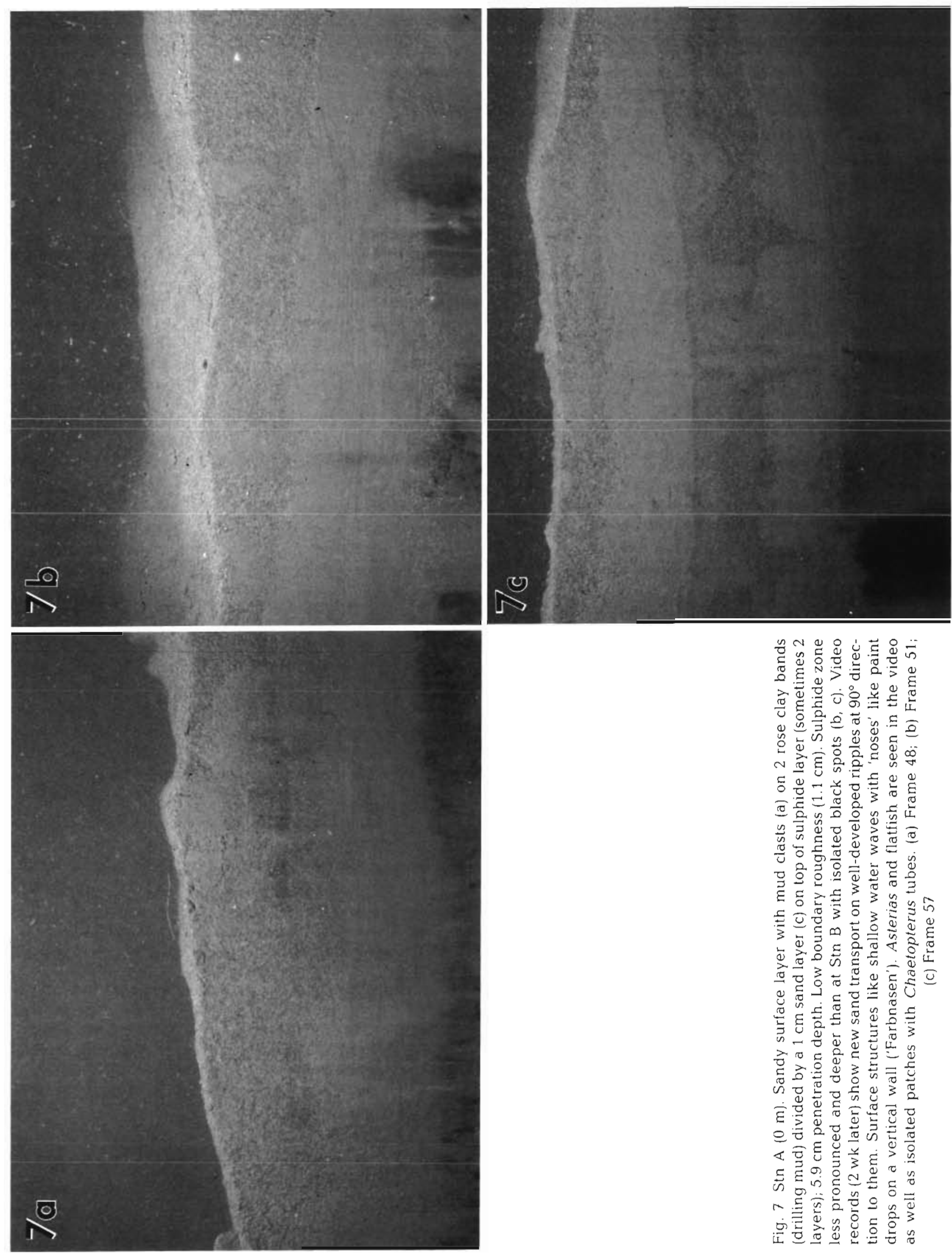


Table 1 List of REMOTS Sediment Profile Images and derived measures (station, frame number, penetration depth of prism, thickness of apparent surface layer, boundary roughness)

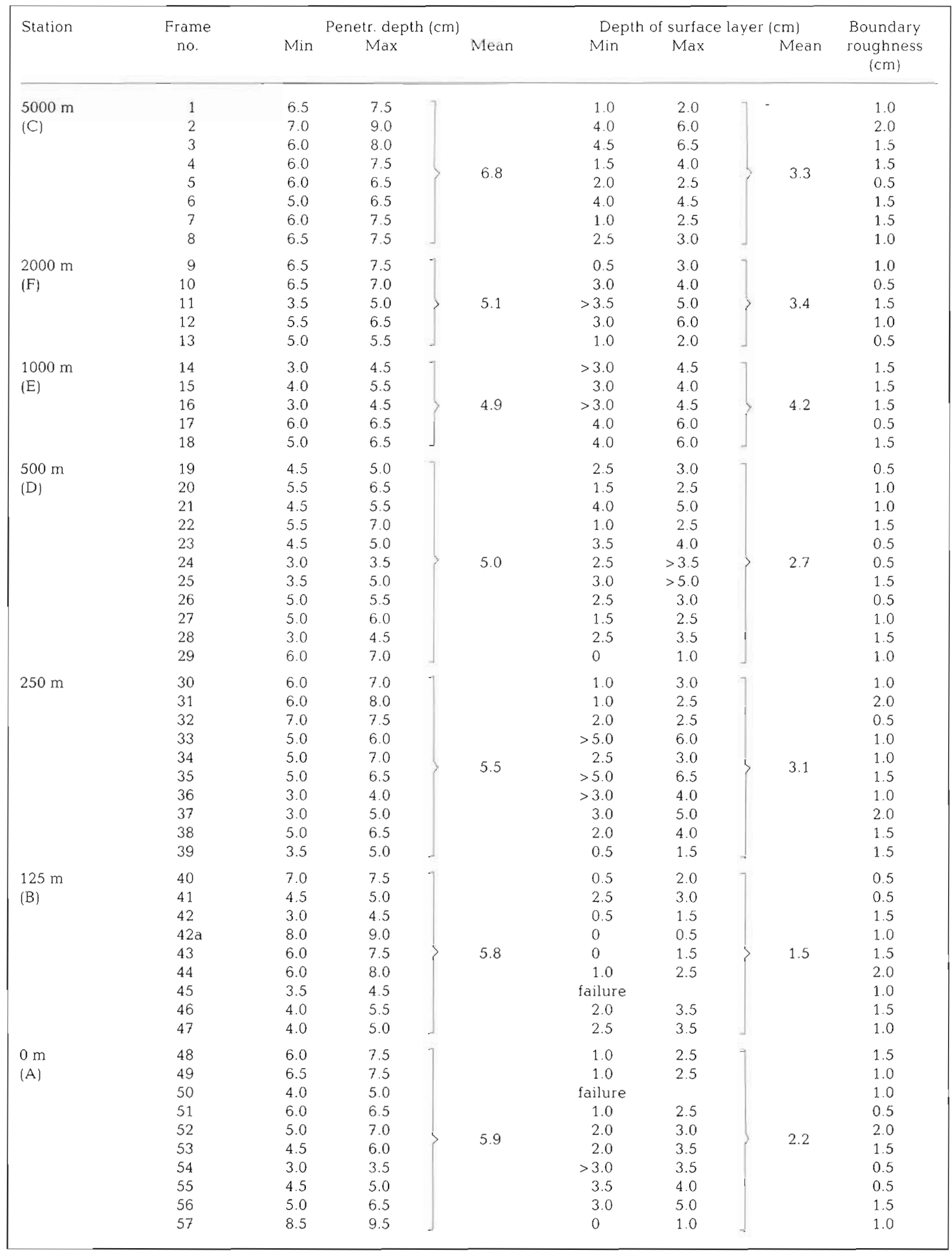




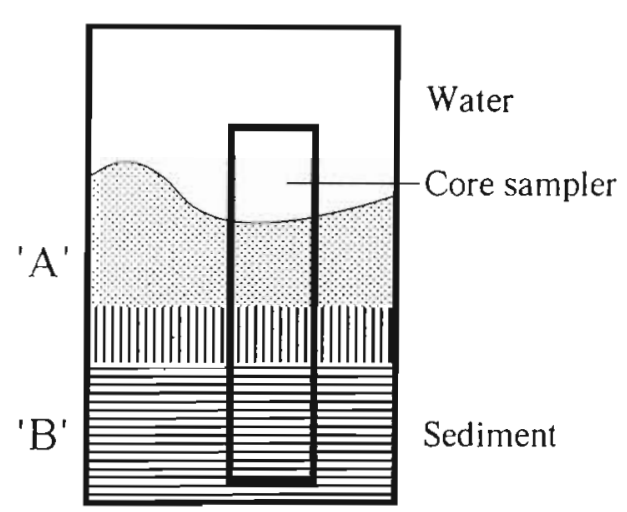

Fig. 8. Schematic REMOTS sediment profile image showing 'new' uncontaminated sediment layers on top ('A') and 'old' potentially contaminated layers below ('B')

$\left.500 \mathrm{~m}, \operatorname{Stn} D_{i} 250 \mathrm{~m}, \operatorname{Stn} C_{i} 125 \mathrm{~m}, \operatorname{Stn} B_{i} 0 \mathrm{~m}, \operatorname{Stn} A\right)$ with 5 to 11 replicates. Further details of the area may be gathered from Daan et al. (1992); station positions and nomenclature are given by Stebbing \& Dethlefsen. (1992). The pictures were recorded on Ektachrome 100 ASA film.

During a second cruise, with RV 'Holland' (26 to 29 March 1990), video recordings were made on 4 stations of the former transect (Stns A, C, E \& G). A SIT (silicon intensified target) camera (Osprey OE 1352) was used mounted on a pan and tilt head in a frame hanging from the anchored ship. The frame was placed from time to time for 10 to 20 s on the sea floor to obtain clear close-up records.

The REMOTS photographs were evaluated in terms of penetration depth of a prism as a measure of sediment compaction, thickness of apparent surface layer, surface boundary roughness (ripple marks), internal secondary layers, sulphide layers, mud clasts and biogenic structures, as well as epifauna. The video records gave valuable supplementary information on the sediment surface features and epifauna or their traces.

\section{RESULTS}

The numerical data from the sediment profile records are summarised in Table 1. The general pattern of the profile images was a sandy surface layer of 0.5 to $2.0 \mathrm{~cm}$. Two weeks later, video records show that these old ripples had been coated with new ripples 'in statu nascendi' or with earlier signs of incipient sand transport, oriented at approximately $90^{\circ}$ to the old ripples. A surface layer of recently transported sand with a mean thickness of 1.5 to $4.2 \mathrm{~cm}$ evenly covered the horizontal layers, the different colours of which showed signs of reduction. In some cases sulphide layers clearly showed organic/hydrocarbon enrichment by the drilling mud, which itself can be clearly traced by the rose colour of the benthonite in the oilbased drilling mud (L. de Jong pers. comm.). In general there was a clear division of 'old' and 'new' sediments at each station in the upper $5 \mathrm{~cm}$, and this is discussed below. The single stations are described in the legends to Figs. 1 to 7, which show REMOTS images from Stns $G$ to $A$, respectively.

\section{DISCUSSION}

The actual sampling pattern must be regarded as an emergency plan to gather at least some of the information planned to be retrieved from a grid sampling scheme around the abandoned drilling site. The adverse weather conditions in early spring 1990 made proper sampling difficult. The results show that the seafloor was also heavily affected by storm and current action as can be seen from the ripple marks in $40 \mathrm{~m}$ depth and the video records of new sediment transport on top of old ripples. The presence of ripple marks makes the application of any diagenetic models questionable. From this and the general pattern of the REMOTS pictures (Fig. 8) it can be concluded that the oxygenated sandy surface layer in the investigation area was moved by current action after drilling activities had ended, and therefore is not primarily contaminated with drilling cuttings (low toxicity oil-based mud - OBM). This has serious implications for any further analysis of sediment samples (including meiofaunaj since it is not clear which fraction of any sample is from the uncontaminated surface layer ' $A$ ' (up to $6.5 \mathrm{~cm})$ and which from the potentially affected layer 'B' (Fig. 8).

The stations look generally rather uniform although there is a clear concentration of sulphide layers at Stn $B$ and less pronounced signs of sediment contamination at the central station (A) and as far away as $500 \mathrm{~m}$ from the drilling site. However, the stated distances of stations to the drilling site must be accepted with the provision that, even with correct navigation and positioning, the centre buoy and the anchored ship moved in the current and the resulting error may amount to up to $100 \mathrm{~m}$ or more. Nevertheless, it has been shown that imaging methods prove to be a powerful tool (even under difficult circumstances) to rapidly document general features of the sediment surface and the upper sediment layers which could not be retrieved by other means. There remains, however, a need for further investigations with REMOTS and video in combination with other traditional methods (Rumohr 1990) in a 'fresh' gradient at an active drilling 
site to demonstrate the acute effects of contamination where they are not masked by secondary sediment movements and alterations.

A complete set of benthic community data for the workshop is available from M. Carr, Plymouth Marine Laboratory, UK

Acknowledgements. We gratefully acknowledge valuable comments and criticisms on this manuscript by Loes de Jong, Carlo Heip and Paul Kingston

\section{LITERATURE CITED}

Daan, R., van het Groenewoud, H., de Jong, S. A., Mulder, M. (1992). Physico-chemical and biological features of a drill- ing site in the North Sea, 1 year after discharges of oilcontaminated drill cuttings. Mar. Ecol. Prog. Ser. 91. $37-45$

Rumohr, H. (1990). Photographic evidence of changes in the sediment. AMBIO Spec. Rep. 7: 11

Rumohr, H. (1991a) (ed.). Imaging methods in benthx ecology, report of the workshop. In: Keegan, B. (ed.) Activity Report 1988-1991, COST 647, CEC, Brussels, p. 311-351 Rumohr, H. (1991b). Utility of imaging methods in benthic research. In: Keegan, B. (ed.) Activity Report 1988-1991, COST 647, CEC, Brussels, p. 335-340

Rhoads, C., Germano, D. (1987). Interpreting long-term changes in benthic community structure: a new protocol. Hydrobiologia 142: 291-308

Stebbing, A. R. D., Dethlefsen, V (1992). Introduction to the Bremerhaven Workshop on Biological Effects of Contaminants. Mar. Ecol. Prog. Ser. 91: 1-8 